\title{
Orbital dermoids: clinical presentation and management
}

\author{
ROBERT P. SHERMAN, ${ }^{2}$ JACK ROOTMAN, ${ }^{2}$ AND JOCELYNE S. LAPOINTE ${ }^{3}$ \\ From the 'Department of Ophthalmology, University of British Columbia, Vancouver; \\ the ${ }^{2}$ Department of Ophthalmology and Pathology, University of British Columbia and Vancouver \\ General Hospital, Vancouver; and the ${ }^{3}$ Department of Radiology, Vancouver General Hospital, \\ Vancouver, Canada
}

SUMmaRY The authors have reviewed 15 cases of orbital dermoids representing $6 \%$ of orbital tumours seen at the University of British Columbia Orbital Clinic. They tended to occur as either asymptomatic superficial lesions in children or as complicated deep lesions in adolescents and adults. The superficial lesions were as frequent medially as laterally and could be dealt with by a direct uncomplicated surgical approach. The deep lesions in contrast, were frequently extensive and difficult to remove, requiring careful preoperative planning. Sites of origin, presentation, differential diagnosis, and management are discussed.

Dermoid cysts occur in the orbital and periorbital region presenting in a variety of ways depending upon the site of origin, size, and rapidity of growth. The frequency of occurrence varies with the age group being studied. ${ }^{1-3}$ and the particular interest of the centre. In the University of British Columbia orbital clinic we have noted a range of presentations from benign, isolated masses, to complicated and frequently misdiagnosed recurrent tumours with and without fistulisation. From our experience there appear to be two types of dermoid cysts seen in clinical practice. One presents as a simple or localised lesion and the other as a complicated one. The difference is based on the site of origin, location within the orbit, and the histological structure of the dermoid.

\section{Materials and methods}

We have reviewed all cases of histologically confirmed orbital dermoids seen in the orbital clinic between 1975 and 1982. All cases were referred for management to a single individual, eight presenting as primary lesions and five following previous surgery. Diagnostic investigations included, when applicable,

Correspondence to Dr Robert P. Sherman, Department of Ophthalmology, University of British Columbia, 2550 Willow Street, Vancouver, BC, Canada V5Z 3N9. computed tomography, plain and tomographic $x$ rays, and ultrasound.

Surgical approaches included two lateral, nine anterior, one combined orbitotomy, and one excision from the temporal fossa, the approach depending on preoperative localisation. At the time of surgery the site of origin was explored and identified when possible. Postoperatively tumours were submitted for routine pathological study. Follow-up was from five years to eight months.

\section{Results}

From 756 of all types of orbital cases, 13 were dermoids $(2 \%)$, and this represented $6 \%$ of the orbital tumours seen between 1975 and 1982. For the purposes of this study we have divided the dermoids into two groups previously defined by Grove ${ }^{4}$ : superficial (simple), seven cases, and deep (complicated), six cases.

\section{SUPERFICIAL DERMOIDS, TABLE 1}

Clinical presentation All of these cases were infants presenting as a primary referral with asymptomatic mass lesions. None was proptotic or had displacement of the globe. In addition all had essentially normal ocular examinations. The masses were $1 \mathrm{~cm}$ in size and were located superolaterally (three left, one right) 
Table 1a Superficial dermoids

\begin{tabular}{|c|c|c|c|c|c|}
\hline Patient & Sex & $\begin{array}{l}\text { Age of } \\
\text { initial signs } \\
\text { and symptoms }\end{array}$ & $\begin{array}{l}\text { Age when } \\
\text { presented }\end{array}$ & Presentation & Suture of origin \\
\hline 1 & $\mathbf{F}$ & 19 months & 2 years & $\begin{array}{l}\text { Asymptomatic } 1 \mathrm{~cm} \text { mass above medial canthal tendon. Firm, } \\
\text { attached to bone, extending posteriorly }\end{array}$ & Left trochlear region \\
\hline 2 & $\mathbf{M}$ & 5 months & 7 months & $\begin{array}{l}\text { Asymptomatic } 1 \mathrm{~cm} \text { palpable firm cystic mass in medial } \\
\text { canthal area }\end{array}$ & Left trochlear region \\
\hline 3 & $\mathbf{M}$ & Birth & $21 / 2$ years & $\begin{array}{l}\text { Droopy left upper lid with non-mobile mass extending } \\
\text { laterally under notched orbital rim }\end{array}$ & Left Z-F suture \\
\hline 4 & $\mathbf{M}$ & 9 months & 11 months & $\begin{array}{l}\text { Asymptomatic } 2 \mathrm{~cm} \text { slightly mobile non-tender mass } \\
\text { extending around orbital margin under lateral aspect of } \\
\text { right brow }\end{array}$ & Right temporalis fossa \\
\hline 5 & $\mathbf{F}$ & 1 year & 2 years & $\begin{array}{l}\text { Asymptomatic } 1 \mathrm{~cm} \text { mobile mass adherent to bone over left } \\
\text { lateral canthus, widening of left zygomatico frontal suture }\end{array}$ & Left Z-F suture \\
\hline 6 & $\mathbf{M}$ & Birth & 6 months & $\begin{array}{l}\text { Asymptomatic } 1.5 \mathrm{~cm} \text { palpable mobile mass superior } \\
\text { temporal aspect of left orbital rim }\end{array}$ & Left Z-F suture \\
\hline 7 & $\mathbf{M}$ & Birth & 14 months & $\begin{array}{l}\text { Asymptomatic } 1 \mathrm{~cm} \text { mass in medial superior left anterior } \\
\text { orbit }\end{array}$ & $\begin{array}{l}\text { Left ethmoidal lacrimal } \\
\text { suture }\end{array}$ \\
\hline
\end{tabular}

Table 1b Superficial dermoids

\begin{tabular}{|c|c|c|c|c|}
\hline Patient & Investigations & Size & Management & $\begin{array}{l}\text { Follow-up } \\
\text { without } \\
\text { recurrence } \\
\text { (months) }\end{array}$ \\
\hline 1 & $X$-ray tomography, no abnormality & $11 \times 7 \mathrm{~mm}$ & Left anterior orbitotomy & 42 \\
\hline 2 & Clinical & $7 \mathrm{~mm}$ & Left anterior orbitotomy & 21 \\
\hline 3 & Clinical & $\begin{array}{r}10 \mathrm{~mm} \\
8 \mathrm{~mm}\end{array}$ & Left anterior orbitotomy & 42 \\
\hline 4 & Plain $x$-rays normal & $9.5 \times 6 \mathrm{~mm}$ & $\begin{array}{l}\text { Excision from left temporalis } \\
\text { fossa }\end{array}$ & 54 \\
\hline 5 & Clinical & $10 \mathrm{~mm}$ & Left anterior orbitotomy & 54 \\
\hline 6 & $\begin{array}{l}\text { CT scan } 12 \times 6 \mathrm{~mm} \text { mass extending posteriorly into orbit without } \\
\text { bony destruction }\end{array}$ & $8 \times 8 \mathrm{~mm}$ & Left anterior orbitotomy & 12 \\
\hline 7 & $\begin{array}{l}\text { CT scan } 5-8 \mathrm{~mm} \text { mass medial superior left orbit rounded and in } \\
\text { continuity with lid, no extension }\end{array}$ & $8 \times 8 \mathrm{~mm}$ & Left anterior orbitotomy & 11 \\
\hline
\end{tabular}

or superomedially (three left). One child had a mechanical ptosis. The masses were firm, rounded, and appeared fixed to bone.

Investigation and management Two patients were not investigated preoperatively, and of the remaining five three had CT scans, one a plain film, and the other polytomography. The CT scans showed focal, rounded masses without bony change, and the $x$-rays were normal. They were all managed by direct surgical excision.

Location and origin All the medial lesions arose from suture lines in the region just below the trochlea. Three of the lateral lesions arose from the frontozygomatic suture and one from the temporalis fossa (Fig. 1).

\section{CASE PRESENTATION: SUPERFICIAL DERMOID}

This child presented at the age of 14 months with a history of a mass in the superior medial aspect of the orbit and lid on the left side. It was thought to have been enlarging over the three months prior to presentation. On examination there was a firm, nontender, fixed mass. Otherwise the ocular examination was normal (Fig. 2). On investigation the CT scan showed a $1 \mathrm{~cm}$ rounded mass and no bony defect was noted (Fig. 3). The mass was removed intact through an anterior incision and was noted to be attached to an anterior ethmoidal suture.

\section{DEEP DERMOIDS, TABLE 2}

Clinical presentation On presentation four of these patients had a mass (two lateral, one superomedial, and one in the lower lid), one axial proptosis, and one had sudden downward displacement of the eye noted following minor trauma. Five of the cases in this category were referred having had previous surgery, and one had developed recurrent inflammation with fistulisation and scarring of the lateral part of the upper lid. On examination all had normal visual acuity, five had normal extraocular movements, and 


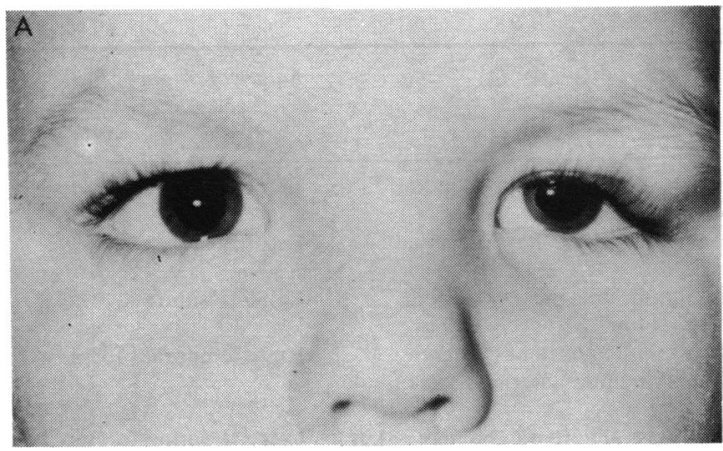

Fig. 1A 21/2year-old boy with mass in left superotemporal lid fixed to bone.

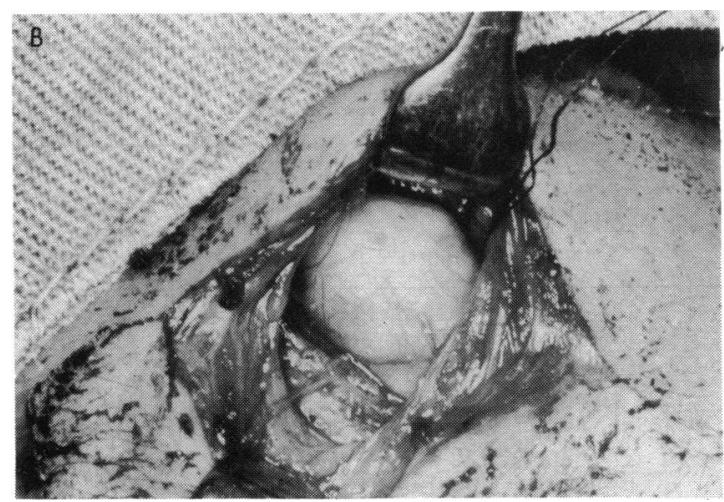

Fig. 1B Surgical appearance of mass arising from left frontozygomatic suture. Note smooth contour and pale colour.

one had vertical diplopia on upgaze owing to the mechanical effect of the tumour mass. The globe was displaced in five patients (two down and medial, one down and lateral, one up, and one axial). One patient had superotemporal choroidal folds. The remaining had normal fundi. One patient was 3 years old, and the remainder were 15 to 40 . In those patients with palpable masses the posterior extent of the lesion could not be determined on clinical examination. Three of the patients had surgical intervention that led to partial removal of their lesions prior to our seeing them, and none of these had a history of severe inflammation with only one developing chronic fistulisation.

Investigation and management All six had CT scans, three had polytomography, and three had ultrasound examinations. The CT scan showed soft tissue mass in all six with three appearing relatively homogeneous, two showing areas of lucency suggesting fat (Fig. 4), and one appearing cystic (Fig. 5). Two had areas of fine calcification, and in four bony defects were noted three of which appeared to be near the

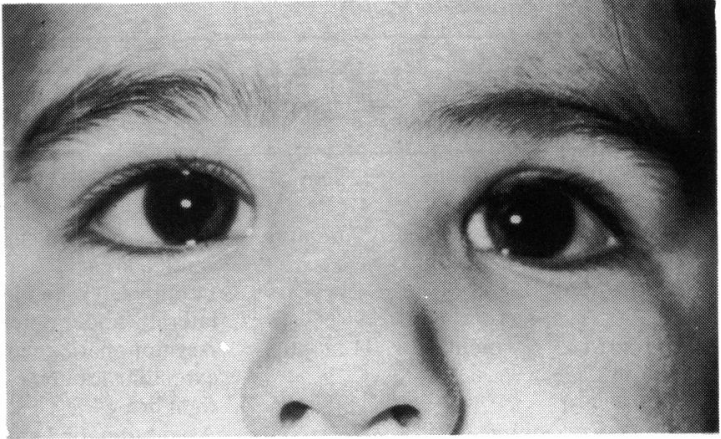

Fig. 214 month-old child with firm, rounded mass in superomedial aspect of left upper lid.

suture of origin. All three who had tomography showed bony defects, and of the patients who had ultrasound two showed cystic areas (also noted on CT), and the third had a solid mass in the lacrimal gland area.

All were managed surgically, three by anterior, two by lateral, and one by combined anterior and lateral orbitotomy. In all an attempt was made to perform the major part of the dissection without rupturing the mass. One was removed intact, four were ruptured and evacuated after dissecting $2 / 3$ to $3 / 4$ of the lesion then fully excised, and one was partially excised because it extended through the superior orbital fissure (Fig. 4). Five have not recurred. None had unusual postoperative inflammation.

Location and origin Three arose from the frontozygomatic suture, two forming a dumb-bell dermoid and one leading to extensive erosion of bone in the lacrimal fossa (Fig. 6). One arose medially just posterior to the trochlea, one from the superior

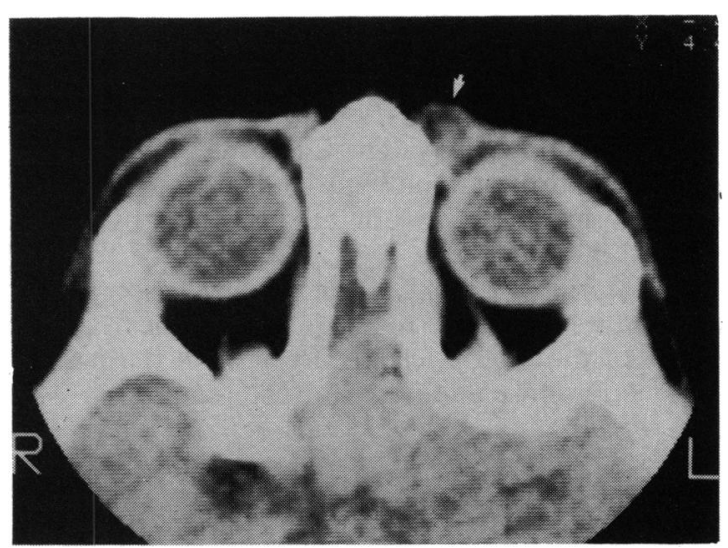

Fig. 3 CT scan showing rounded mass with varying density (arrow) without bony defect. 
Table 2a Deep dermoids

\begin{tabular}{|c|c|c|c|c|c|c|}
\hline Patient & Sex & $\begin{array}{l}\text { Age of initial } \\
\text { onset of signs } \\
\text { and } \\
\text { symptoms }\end{array}$ & $\begin{array}{l}\text { Age when } \\
\text { first } \\
\text { presented }\end{array}$ & $\begin{array}{l}\text { Age when } \\
\text { seen at UBC } \\
\text { clinic (years) }\end{array}$ & Nature of initial presentation & Time to recurrence \\
\hline 8 & $\mathbf{M}$ & 10 years & 22 years & 26 & Firm mass fixed to bone in left lacrimal area & 6 months \\
\hline 9 & $\mathbf{M}$ & 34 years & 34 years & 52 & Proptosis of right eye & 18 years \\
\hline 10 & $\mathbf{F}$ & 13 years & 14 years & 17 & Asymptomatic mass under right eye & 3 years \\
\hline 11 & $\mathbf{M}$ & 37 years & 41 years & 41 & $\begin{array}{l}\text { Diplopia after trauma with } 4 \mathrm{~mm} \text { medial and } \\
\text { downward displacement of left eye with } \\
\text { narrowing of palpebral fissure indentation of } \\
\text { left sup. lat. globe on funduscopy (choroidal folds) }\end{array}$ & Not applicable \\
\hline 12 & $\mathbf{F}$ & 15 years & $161 / 2$ years & $161 / 2$ & $\begin{array}{l}\text { Non-tender, non-inflamled mass in superior } \\
\text { nasal quadrant of left orbit }\end{array}$ & $\begin{array}{l}\text { Referred after surgical } \\
\text { exploration without } \\
\text { excision }\end{array}$ \\
\hline 13 & $\mathbf{F}$ & $1-2$ months & $21 / 2$ months & 3 & Mass right upper lid & $\begin{array}{l}\text { Referred after surgical } \\
\text { exploration without } \\
\text { excision }\end{array}$ \\
\hline
\end{tabular}

Table 2b Deep dermoids

\begin{tabular}{rll}
\hline 8 & $\begin{array}{l}\text { Recurrent inflammation with fistulisation leading to development of a } 20 \times 40 \text { mm firm mass } \\
\text { fixed to bone at left upper lid with draining sinus with cheesy material }\end{array}$ & $\begin{array}{l}\text { Left zygomaticofrontal suture } \\
\text { dumb-bell dermoid orbit and } \\
\text { temporalis fossa }\end{array}$ \\
$\begin{aligned} \text { Left superior orbital fissure } \\
10\end{aligned}$ & $\begin{array}{l}9 \mathrm{~mm} \text { axial proptosis of right eye } \\
\text { of palpebral fissure }\end{array}$ & $\begin{array}{l}\text { Right posterior ethmoidal } \\
\text { sphenoidal suture }\end{array}$ \\
11 & $\begin{array}{l}\text { Not applicable } \\
\text { Cystic fluctant mass medial aspect left orbit with lateral and downward displacement of eye }\end{array}$ & Left Z-F suture \\
12 & Persistent mass in right upper lid & Right Z-F suture
\end{tabular}

Table 2c Deep dermoids

\begin{tabular}{|c|c|c|c|c|}
\hline Patient & Investigations & $\begin{array}{l}\text { Size of } \\
\text { tumour }(\mathrm{mm})\end{array}$ & Management & $\begin{array}{l}\text { Follow-up } \\
\text { without } \\
\text { recurrence }\end{array}$ \\
\hline 8 & CT scan showed mass at left Z-F suture abutting on globe & $\begin{array}{l}7 \times 5 ; 13 \times 8 \\
10 \times 10(3) \\
\text { Dermoid }\end{array}$ & Left anterior orbitotomy & 21 months \\
\hline 9 & $\begin{array}{l}\text { CT scan showed proptosis, bowed medial wall with thinned } \\
\text { lateral wall, large intraconal soft tissue enhancing mass extending } \\
\text { to apex (1977), uniformly expanded orbit, anterior cystic } \\
\text { component/post-solid component }\end{array}$ & Dermoid & Right lateral orbitotomy & $\begin{array}{l}5 \text { years } \\
(\mathrm{CT}) \\
\text { recurrence } \\
\text { noted Feb } \\
1981\end{array}$ \\
\hline 10 & $\begin{array}{l}\text { CT scan Sept. 1978. Soft tissue mass involving anterior and } \\
\text { superior portion of right maxillary sinus and floor of orbit } \\
\text { adjacent to rim. Oct. } 1978 \text {. Slowly growing mass in inferior } \\
\text { medial margin right orbit posterior and inferior to the globe. Oct. } \\
1981 \text {. Extrabulbar soft tissue mass inferior to the right globe with fine } \\
\text { stippled Ca++. Ultrasound suggested cystic mass }\end{array}$ & $\begin{array}{l}36 \times 25 \times 8 \\
(5+) \\
\text { Dermoid }\end{array}$ & $\begin{array}{l}\text { Right anteriolateral } \\
\text { combined orbitotomy }\end{array}$ & 18 months \\
\hline 11 & $\begin{array}{l}\text { CT scan showed a large mass in lacrimal gland region with } \\
\text { indentation and bony change in lacrimal fossa. } X \text {-ray tomography } \\
\text { showed erosion of bone and ultrasound showed a lesion in } \\
\text { lacrimal gland region }\end{array}$ & $\begin{array}{l}30 \times 12 \\
(3+) \\
\text { Dermoid }\end{array}$ & Left lateral orbitotomy & 36 months \\
\hline 12 & CT showed large cystic mass extending into postmedial orbit & $\begin{array}{l}20 \times 10 \times 3 \\
7 \times 6 \times 2(2) \\
\text { Dermoid }\end{array}$ & Left anterior orbitotomy & 36 months \\
\hline 13 & $\begin{array}{l}\text { CT showed small rounded lesion adjacent to lateral border of } \\
\text { right orbit with erosion of bone at orbital margin. No displacement } \\
\text { of mass nor extension into posterior orbit }\end{array}$ & $15 \times 12 \times 6$ & Right anterior orbitotomy & 9 months \\
\hline
\end{tabular}




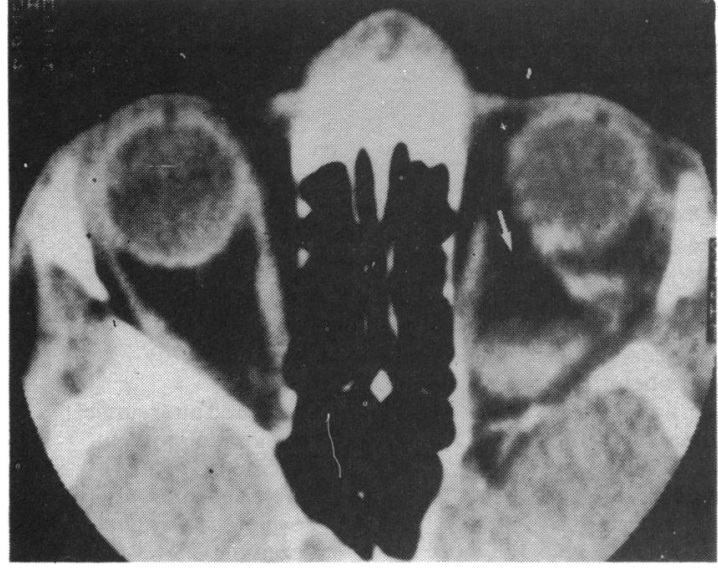

Fig. 4 CT scan showing large, rounded intraconal mass with anterior lucent component (consistent with fat) and posterior solid component (arrow). Note partial absence of sphenoid wing where mass extends to the widened superior orbital fissure.

orbital fissure, and one from a suture just below the posterior ethmoidal artery.

\section{CASE PRESENTATIONS: DEEP DERMOIDS}

\section{CASE 1}

This 17-year-old girl presented in October 1981 with a history of recurrence of a mass in the lower lid and orbit on the right side. Previous to referral she had been explored three times by anterior orbitotomy and by a Caldwell-Luc approach on one occasion. Each time an attempt had been made to remove a cyst which contained a cheesy material. All attempts had led to partial removal with recurrence of a mass and no evidence of inflammation. On examination she had normal vision and extraocular movements

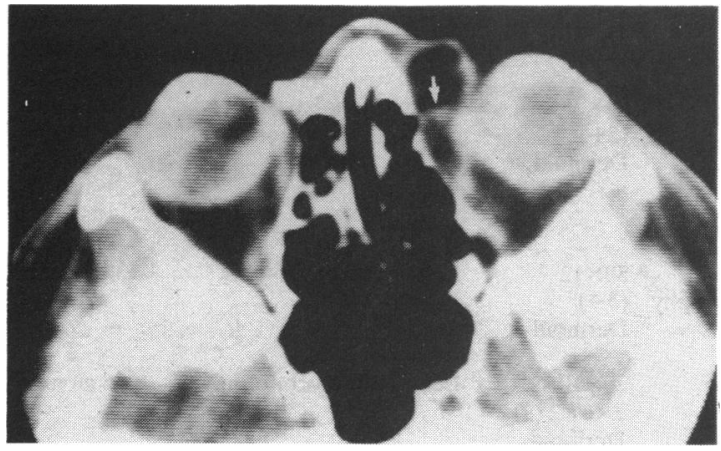

Fig. 5 Large medial cystic mass of orbit. Note opaque band (arrow) extending across cyst. At time of surgery this proved to be the trochlea and tendon of the superior oblique.

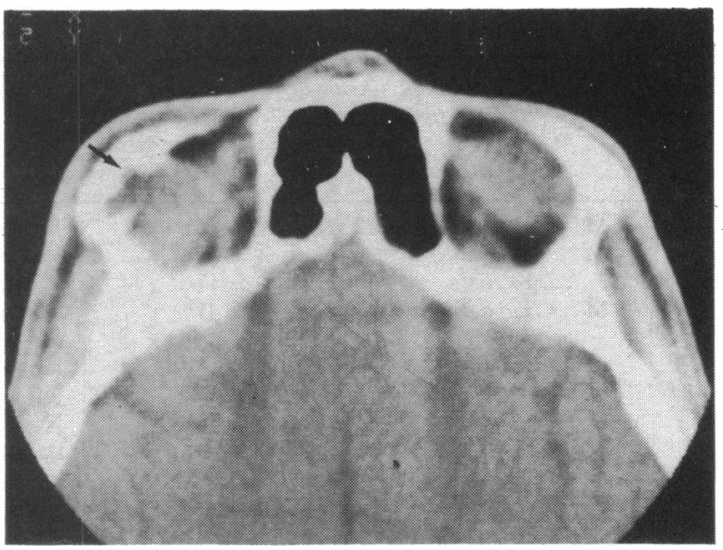

Fig. 6 CT scan showing large mass in lacrimal fossa with erosion of adjacent bone (arrow).

with a $3 \mathrm{~mm}$ swelling and $1 \mathrm{~mm}$ proptosis of the globe. There was a woody, non-tender, diffuse infiltrate in the thickened right lower lid, and the interpalpebral fissure was narrowed (Fig. 7). The fundus was normal.

CT scanning showed an extrabulbar, soft tissue mass located inferior to the right globe with a slight swelling of the optic nerve and apparent incorporation of the inferior oblique and inferior rectus muscles. Fine stippled calcification was present in the mass, and there was expansion and erosion of the orbital floor with a small defect in the posterior medial wall of the orbit (Fig. 8). Ultrasound showed a cystic mass.

The patient underwent a combined lateral and anterior orbitotomy. An inferior and posterior smooth encapsulated cystic mass was identified and noted to be contiguous with an anterior scarred multicystic mass. It extended to the orbital apex just beneath the medial rectus and appeared to arise from a pit in the posterior ethmoidal suture just below the posterior ethmoidal artery. Anteriorly the scar tissue encased the inferior oblique which was dissected free and resutured to the periostium behind the lacrimal

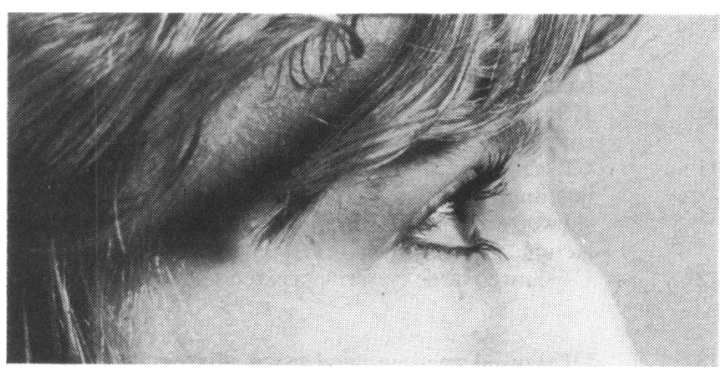

Fig. 7 Lateral photograph of 17-year-old girl with thickened right lower lid and raised globe. 


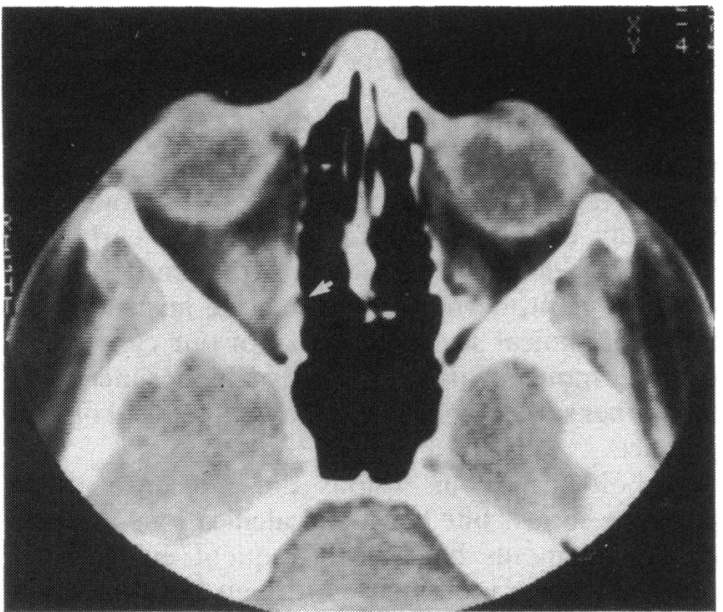

Fig. 8 CT scan showing posterior aspect of irregular orbital mass immediately below optic nerve and abutting on medial orbital wall. Note small dehiscence in posterior medial orbital wall (arrow).

crest. During resection sebaceous material leaked from the major cyst, but total extirpation was achieved.

Pathologically the tissue consisted of granulomatous inflammation, scarring, fat, cholesterol clefts with foreign body reaction, focal calcification, an area of keratinised epithelium, and many sebaceous adnexal structures.

\section{CASE 2}

This patient first presented at age 21 with a mass located in the outer aspect of the left upper lid which appeared to be fixed to the bone. The lesion was extirpated, and following removal he developed recurrent episodes of gradually increasing localised inflammation, tumefaction, and cyclical drainage. A repeat attempt at removal was made three years later

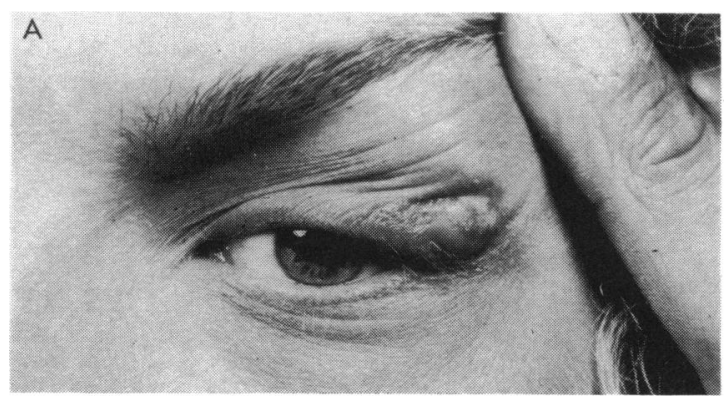

Fig. 9A Left eye of 21-year-old patient showing mass and draining fistula in superolateral aspect of lid. with recurrence of the lesion leading to progressive scarring and persistent fistulisation (Fig. 9A). The patient was referred to the orbital clinic, at which time review of photographs revealed the lesion in childhood (Fig. 9B). Retrospective study of the pathology showed granulomatous inflammation with evidence of fat, and a single birefringent hair was noted.

On examination he had normal ocular function with a $2 \times 1.5 \mathrm{~cm}$ mass in the outer aspect of the left upper lid. The mass was firm, attached to underlying bone, and associated with a fistula and injection of the lid (Fig. 9A). There was a tender preauricular node, and the fistula appeared to be draining a cheesy material which could be extruded with pressure. CT scan showed a mass extending from the fronto zygomatic suture to the globe with a focal defect in bone.

He underwent a left anterior orbitotomy, and a dermoid was removed and found to originate from and extend through the frontozygomatic suture. The dumb-bell dermoid was removed from the temporalis fossa and the orbit. In addition the fistula was excised from the lid (Fig. 10).

Pathologically the tissue was made up of dense collagen, focal areas of granulomatous inflammation, keratinising epithelium with adnexal structures, foreign body reaction to cholesterol, and fat.

\section{PATHOLOGY}

Histologically all were confirmed as dermoid cysts. The superficial dermoids were lined by keratinising squamous epithelium with small abortive adnexal structures (Fig. 11). One had focal disruption of the wall with granulomatous inflammation. In contrast all of the deep dermoids had varying degrees of granulomatous inflammation and scarring with deposition of sebaceous material into surrounding tissues. Several had massive sebaceous adnexal structures, two had focal areas of calcification, three had giant cell reactions to cholesterol, and one consisted of a cyst almost completely lined by epithelioid and giant cells (Fig. 12). In one case the granulomatous reaction had eroded through the inner table of the adjacent bone.

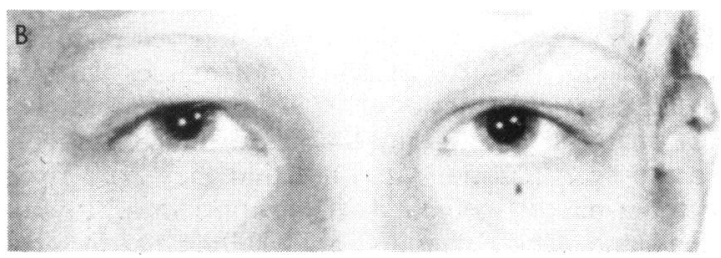

Fig. 9B Same patient at age 15 prior to any surgery. Note mass in left superolateral upper lid. 


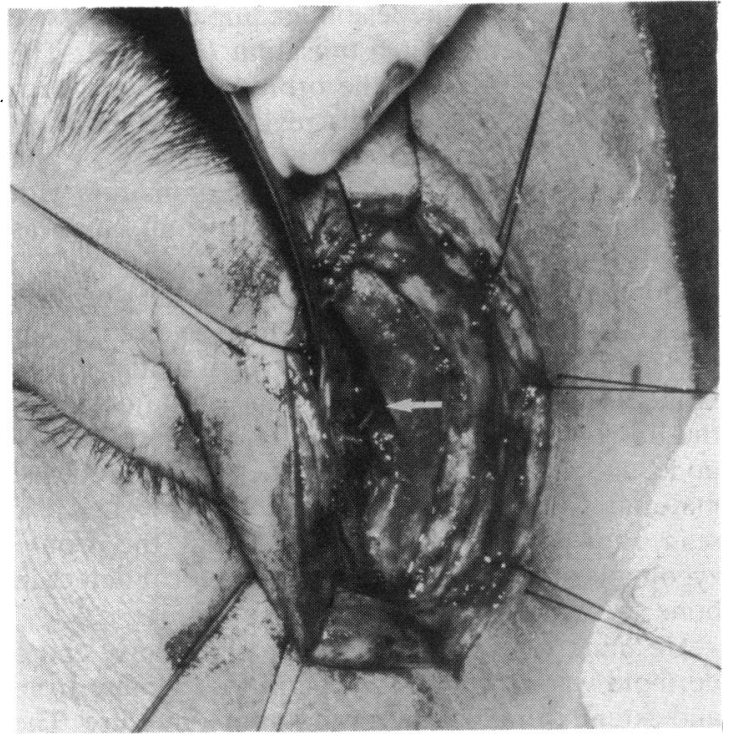

Fig. 10A Photograph taken at time of surgery showing anterolateral incision. Note tip of Bowman probe (arrow) extending through tract of fistula to the region of the frontozygomatic suture.

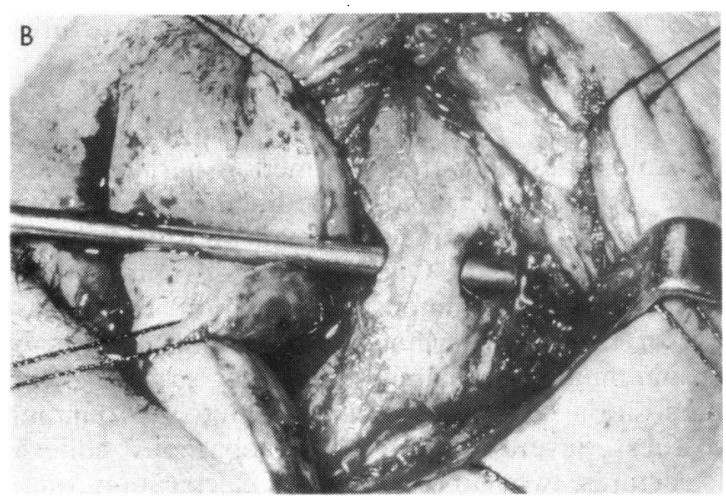

Fig. 10B Suction tip extending through defect in frontozygomatic suture into temporalis fossa.

\section{Discussion}

Dermoid cysts are developmental choristomas comprising 3 to $9 \%$ of all orbital masses with an average in pooled series of $4.7 \%{ }^{4}$ In this series it was $6 \%$ of orbital tumours and $2 \%$ of all orbital conditions. In the head and neck it is felt that they arise from ectodermal rests 'pinched off' at suture lines. ${ }^{2} 10 \%$ of head and neck dermoids ${ }^{5}$ are orbital, and in most series the upper outer quadrant dominates. In contrast ours occurred in equal numbers temporally and medially. We had a dominance of left orbital lesions. However, this is not the case in other series. ${ }^{267}$

The natural history of dermoids is slow expansion and, depending on their site, displacement of adjacent structures. Anterior or superficial dermoids are generally easily recognised and treated early. As noted here deeper seated lesions frequently present later as 'giant' dermoids and may be misleading in terms of clinical size. Six $(46 \%)$ of our cases were deep dermoids, which represents a higher incidence than other series owing to the bias of a referral orbital practice.

Pathologically our lesions did not differ from previous series, but two had calcification, and the deeper dermoids had more frequent evidence of rupture with granulomatous foreign body reaction and extensive sebaceous structures. It is of interest that in spite of histological evidence of previous rupture in six of our cases with chronic granulomatous reaction none of our patients presented with a history of bouts of acute orbital inflammatory signs and symptoms. The single case with a fistula had a chronic low grade localised inflammatory reaction.

The simple dermoids arise from anterior suture lines, and it is important to note that they have easily palpable posterior margins denoting a lack of deeper origin or extension. Clinically this is an important clue. On the other hand complicated dermoids arise from deeper sites and are frequently misdiagnosed as to extent and complexity, especially when their anterior margin is palpable superficially. Because of their deep origin they present in an older age group either with proptosis or a mass with indistinct posterior margins. Other clues to a deeper location are evidence of visual or oculomotor disturbance noted in other series. ${ }^{7}$

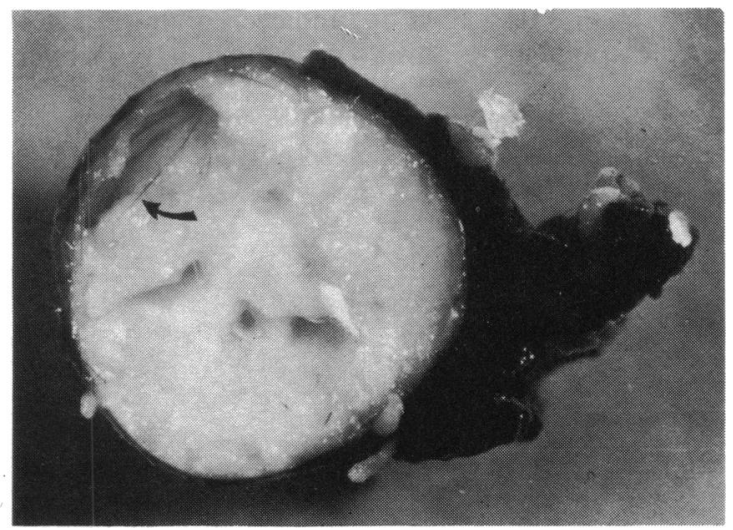

Fig. 11A Gross photograph of superficial dermoid cyst showing thin wall, keratin debris, and hair (arrow). 


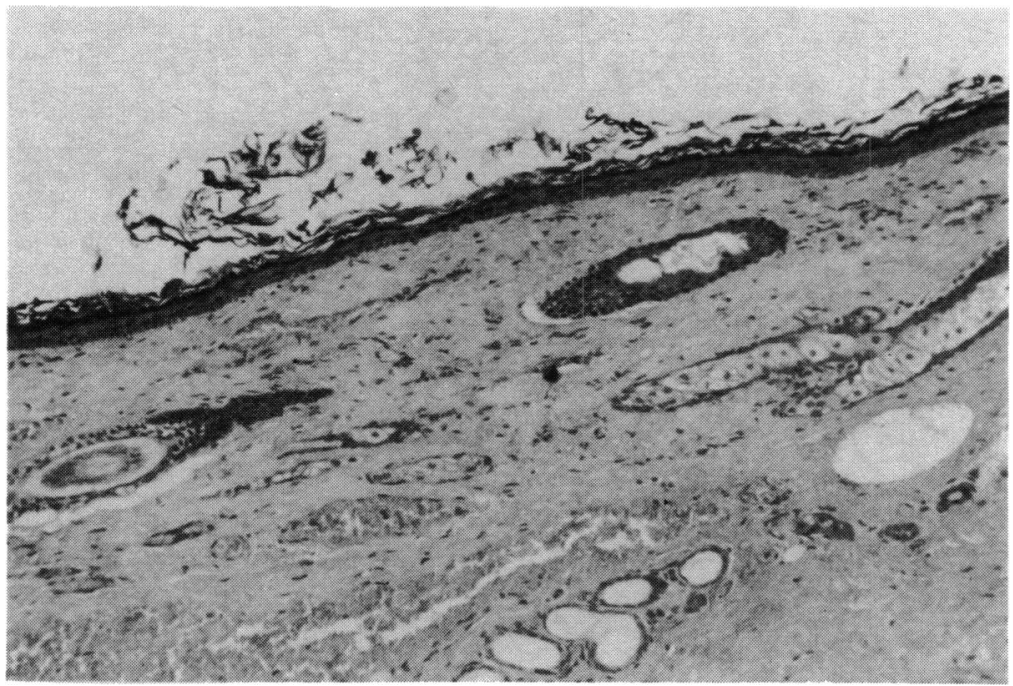

Fig. 11B Cyst wall showing keratinised lining, abortive sebaceous structures, and hair. (Haematoxylin and eosin, $\times 6$ ).

Thorough and careful investigation is necessary in order to distinguish between deep and superficial dermoids, since deep dermoids may extend beyond the orbit into the temporalis fossa as shown here (Fig. $9 A, B)$ or intracranially. ${ }^{2}$ Recognition of size, character, extension, and bony defects are important clues. Superficial dermoids were localised, small, anterior, and had no bony defect versus the deep lesions which in 5 out of 6 showed a bony defect and were large. Axial and coronal CT scanning identified the size, extent, and suspicion of bony change. Polytomography should then confirm the specific nature of the bony abnormality. Characteristically the giant dermoids have well defined margins and, in the case of three of ours, may have a lucent area (negative Houndsfield values) suggesting sebaceous material (Figs. 3, 4, 13). Calcification may be noted and, in the case of a lesion in the lacrimal fossa region, can suggest the differential diagnosis of a malignant tumour. However, an important feature that may help to distinguish the two is the observation that bony change tends to include or extend only to the frontozygomatic suture in the case of a dermoid versus a lacrimal tumour (Fig. 13A,B). We found ultrasound useful to demonstrate the cystic nature of the lesion when present but, because of internal echoes, they may be misrepresented as solid tumours. In addition we found lesions in the lacrimal fossa or

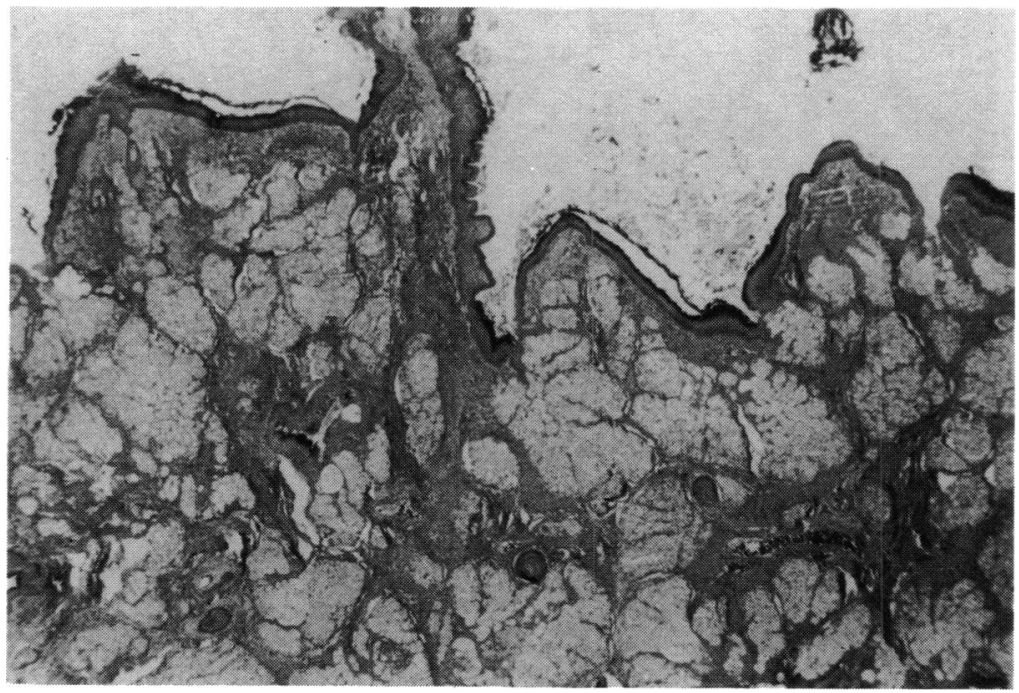

Fig. 12A Wall of giant dermoid cyst showing massive sebaceous adnexal structure. (Haematoxylin and eosin, $\times 1 \cdot 5$ ). 
Fig. 12B Histology of part of the cyst wall showing calcification surrounded by scarring and many lipid laden cells. (Haematoxylin and eosin, $\times 7)$.

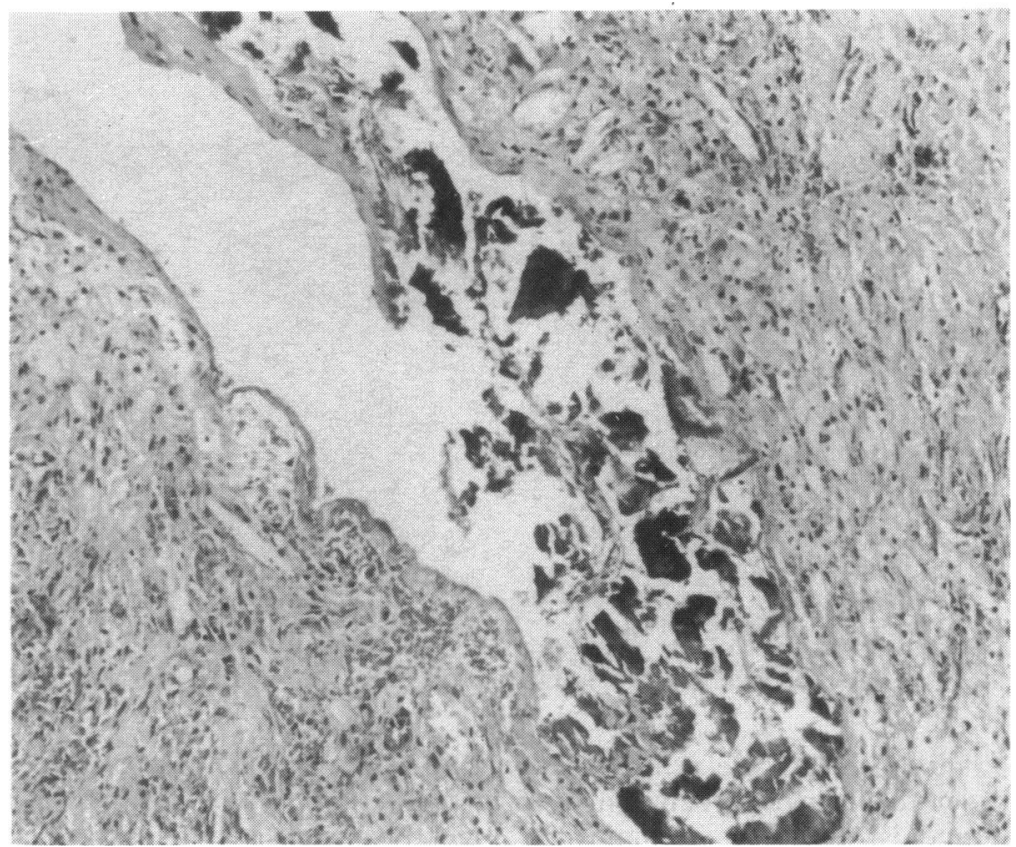

deep in the orbit were more difficult to demonstrate effectively by ultrasound.

The location, relationship to bone, and cystic nature help to identify dermoids. The differential diagnosis depends on the location of the mass. In the region of the lacrimal gland primary and secondary lacrimal tumours should be considered, especially if there is evidence of bony erosion or calcification. Medially retention cysts or mucoceles can be distinguished by their relationship to the sinuses, evidence of focal destruction of the bones, and associated opacification of the sinuses. We have,
Fig. 12C Note hair (arrow) surrounded by scar and inflammatory reaction. (Haematoxylin and eosin, $\times 14 \cdot 5$ ).

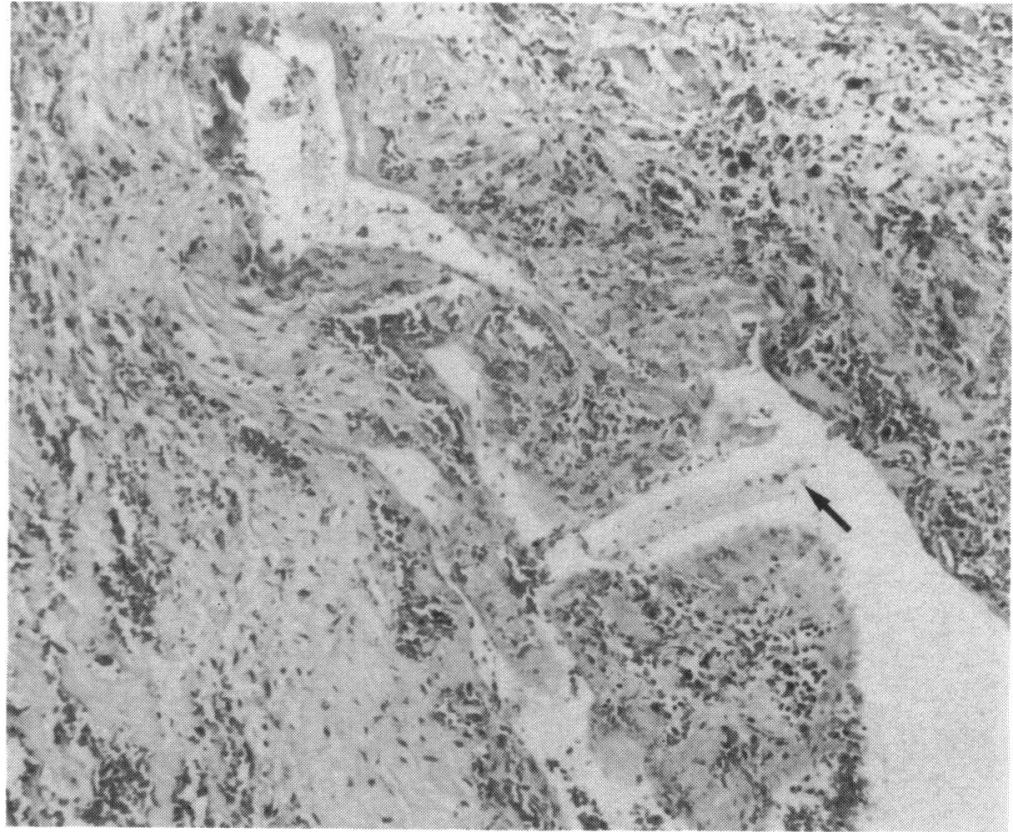




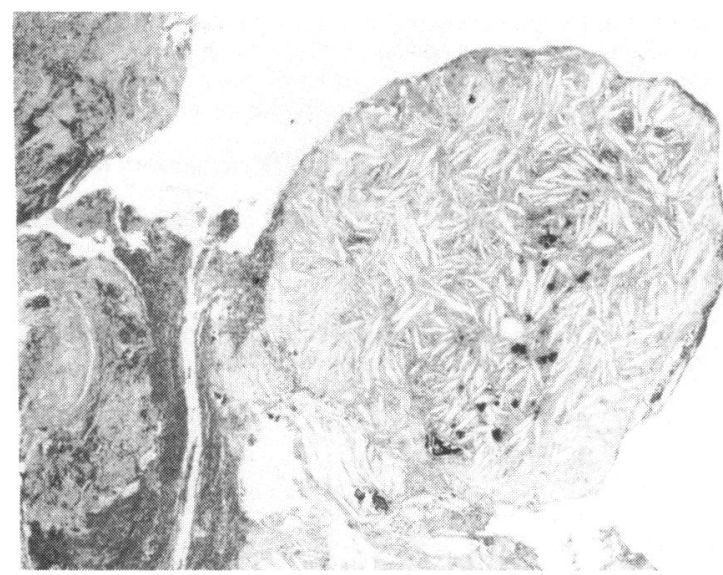

Fig. 12D Nodule of tissue from cyst containing cholesterol clefts surrounded by foreign body reaction. (Haematoxylin and eosin, $\times 1 \cdot 6$ ).

however, recently encountered two cases of orbitofrontal dermoids and one mucocele that had identical features on investigation. Rarely an encephalocele may occur medially in which case a focal defect continuous with the cranial cavity may be noted, generally at the root of the nose. However, it may be difficult to distinguish between the two. Contrast metrizamide injected into the cerebrospinal fluid may allow for a distinction between an encephalocele and

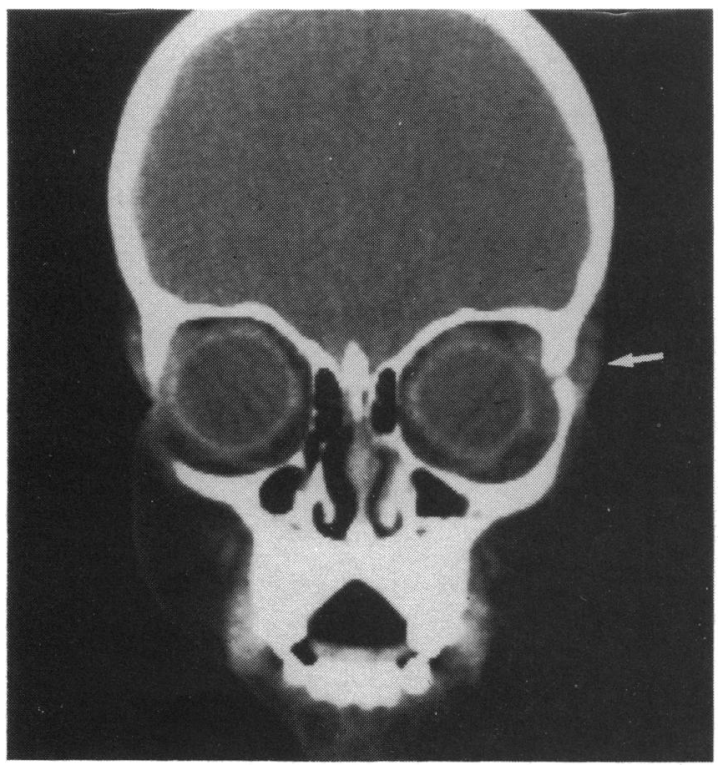

Fig. 13A CT scan of deep orbital dermoid extending through frontozygomatic suture into temporalis fossa (arrow). other lesions involving the orbit, sinuses, and intracranial cavity. Any of the solid tumours of the orbit should be included in the differential diagnosis, especially if there is a focal bony defect.

The treatment of these lesions can be complicated owing to size, location, and involvement of orbital structures and should not be undertaken by the occasional orbital surgeon. The operative approach should be based on thorough preoperative assessment of size, location, extent, and relationship to adjacent structures. In principle the base of the lesion is felt to be the active growth centre, but total removal is mandatory to prevent recurrence or fistulisation. We attempt to dissect the total lesion intact when small and in the case of the giant ones suggest doing the major dissection around the firm lesion before evacuating it, since the planes of dissection are more clearly defined when it is intact.

Because of the large size of these lesions evacuation followed by microdissection of the lining is frequently necessary. The simple or superficial lesions are well handled by a direct approach over them. The deep ones may extend intracranially and require anterior, lateral, or combined orbitotomy for total extirpation. As long as the total lining and contents of the dermoid are removed intraoperative rupture does not appear to lead to early or late postoperative morbidity. Rarely complete removal may be impossible because of the potential to produce serious functional deficits when the lesion extends apically to the intracranial cavity. Some people have advocated marsupialisation $^{8}$ in this circumstance, but this may be dangerous in view of the potential for infection, and we would not recommend it. In one of our cases the incomplete removal with total evacuation has allowed considerable intervals between procedures with preservation

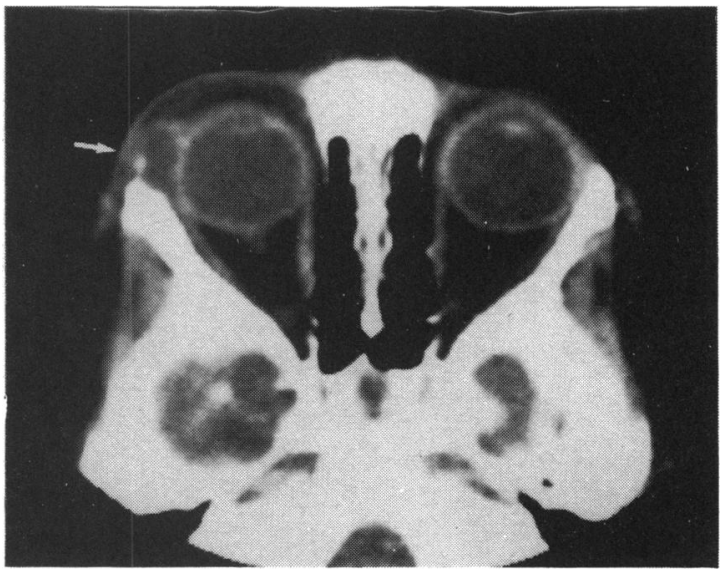

Fig. 13B Axial scan of same lesion. Note lucent central area and focal calcification (arrow). 
of ocular function. The best management remains total removal, and all attempts should be directed toward this.

\section{References}

1 Jones IS, Jakobicc FA, Nolan BT. Patent examination and introduction to orbital disease. In: Duane TD, ed. Clinical ophthalmology II: the orbit. Hagerstown: Harper and Row 1976; 1-30.

2 Pfeiffer RL, Nicholl RJ. Dermoid and epidermoid tumours of the orbit. Arch Ophthalmol 1948; 40: 639.
3 Moss HM. Expanding lesions of the orbit. A clinical study of 230 consccutive cases. Am J Ophthalmol 1962; 54: 761.

4 Grove AS Jr. Orbital disorders: diagnosis and management. In: McCord CD Jr. ed. Oculoplastic surgery. New York: Raven Press. $1981: 274-7$

5 Pollard ZF, Calhoun MD. Decp orbital dermoid with draining sinus. Am J Ophthalmol 1975; 79: 31()-13.

6 Cullen JF. Orbital diploic dermoids. Br J Ophthalmol 1974; 58: $105-6$.

7 Grove AS Jr. Giant dermoid cysts of the orbit. Ophthalmology 1979; 86: 1513-20.

8 Kennedy RE. Marsupilization of inoperable orbital dermoids. Trans Am Opthalmol Soc 1970); 68: 146-64. 